\title{
La explotación sexual frente al Derecho Penal
}

\author{
Sexual exploitation against the Criminal Law \\ A exploração sexual contra Direito Penal
}

\section{RESUMO}

O presente artigo tenta fazer uma análise crítica sobre o trabalho sexual e sua exploração por parte de terceiros. A abordagem desses problemas são realizados desde a perspectiva do direito penal. Na Ámerica Latina, especialmente em. Tento em vista suas características e as limitações às que deve estar submetido quando é utilizado como um instrumento de exploração sexual.

\section{PALAVRAS-CHAVES}

Exploração sexual, Tráfico e comércio de pessoas, Repressão penal.

\section{RESUMEN}

El presente artículo intenta hacer un análisis crítico sobre el trabajo sexual y su explotación por parte de terceros. El abordaje de esta problemática se lleva a cabo desde la perspectiva del Derecho Penal -en América Latina, especialmente en Brasil- teniendo en cuenta sus características y las limitaciones a las que debe estar sometido cuando es utilizado como un instrumento de control de la explotación sexual.

\section{PALABRAS CLAVE}

Explotación sexual, Tráfico y comercio de personas, Trata de personas, Represión penal.

\section{ABSTRACT}

This article tries to make a critical analysis of sex work and exploitation by third parties. Addressing this issue it is conducted from the perspective of criminal law -in Latin America, especially in Brazil, considering its characteristics and limitations that must be subjected when used as an instrument of control sexual exploitation.

\section{KEYWORDS}

Sexual exploitation, Trafficking and trade in people trafficking, Criminal repression.

\section{JOSÉ FERNANDO GONZÁLEZ}

Brasileño. Miembro jubilado del Ministerio Público del Rio Grande do Sul. Abogado criminalista. Profesor de Derecho Procesal Penal de la Facultad de Derecho de la Universidad Federal de Pelotas, RS, BR. Actualmente es candidato a doctor de la Universidad de Buenos Aires, en el área de Derecho Penal. jfg.adv@terrra.com.br 


\section{INTRODUCCIÓN}

El fenómeno de la prostitución será evaluado desde el estigma social a que está subordinado a partir de la difusión de los dogmas del catolicismo y sus consecuencias en el campo del Derecho, y muy especialmente en el Derecho Penal. Además, será examinada una sentencia de la Corte Constitucional de Colombia, que ha reconocido el derecho a la indemnización por despido injusto de una trabajadora sexual en este país, lo que representa un precedente importante en la defensa de la dignidad humana en el área de estudio.

En el ámbito de la explotación sexual, específicamente, se hará hincapié en el papel del Derecho Penal como un instrumento de represión de las prácticas que preocupan en gran medida a las organizaciones internacionales, en particular la explotación sexual de niños y el tráfico y comercio de personas. Para entender/demostrar hasta qué punto los tratados y convenciones influyen en los Estados miembros para que adopten una legislación penal cada vez más rigurosa, el estudio se referirá a los dispositivos penales de otros países como Colombia y Argentina.

En resumen, analizando los hechos y los datos, no quedan dudas de que la explotación sexual y el comercio de personas son realidades muy preocupantes, que exigen la adopción de medidas restrictivas urgentes. La cuestión que se impone es descubrir cuál debe ser precisamente la función del Dere- cho Penal como instrumento de represión de estas conductas.

\section{Prostitución. Trabajo sexual}

Muchos son los aspectos que se pueden investigar en la prostitución: desde el punto de vista de la exclusión social a que están sometidos aquellos involucrados en ese oficio, hasta las consecuencias económicas derivadas de su práctica, según la perspectiva de lucro; desde su origen milenario hasta los tiempos modernos, teniendo en cuenta las múltiples caras que ha ostentado* frente a la moral dominante. Cierto es que el comercio del cuerpo sigue retando sociólogos y juristas, sobre todo considerando sus "características" actuales. En países como Brasil, marcados por grandes diferencias de oportunidades e ingresos, es sabido que será en las comunidades más pobres donde la prostitución va a conseguir sus "trabajadores", seducidos por la expectativa de obtener ganancias fácilmente a través de la venta del cuerpo. Mujeres predominantemente jóvenes y hermosas son llevadas a adherir a lo que se suele llamar "la más antigua de las profesiones", en una relación peculiar de comercio, que encuentra mercado por el hecho de ser el sexo la más grande fuente de placer del ser humano.

\footnotetext{
Paulo Roberto Ceccarelli. Psicólogo y psicoanalista a quien nos vamos a referir en otras oportunidades de este trabajo, enseña que determinadas formas de prostitución ya fueron vinculadas a divinidades, como en las primeras civilizaciones de Mesopotamia y del Egipto, y que en la antigua civilización griega la prostitución era una forma de ganarse la vida como cualquier otra, además de ser una práctica controlada por el Estado.
} 
La prostitución es la relación carnal íntima que ocurre mediante recompensa, en general a través del pago en dinero, sin que haya un vínculo de afecto entre las partes. A propósito, la ausencia de afecto parece ser considerada una especie de "principio" entre los actores del "comercio", tal como es retratado en la película Mujer bonita, de Garry Marshall, con Richard Gere y Julia Roberts. En esa película un millonario, Edward, contrata los servicios de una prostituta, Vivian, quien deberá servirle durante una semana, y la relación entre ellos termina por pasar al campo afectivo. Al darse cuenta de que Vivian está enamorada, Kit, que también es prostituta, hace duras críticas a la compañera, reprochándola por no haber respetado la "regla fundamental", al besar a su cliente en la boca, lo que le ha permitido enrollar de una forma no profesional.

Ciertos rasgos de esa actividad, y las reglas de mercado a que es sometida, permiten considerarla un trabajo; esto, porque -como enseña el profesor Misael Tirado Acero (2011, p. 253) - "los actores pactan una tarifa y las condiciones sobre las cuales estará mediada la relación, rompiendo los patrones tradicionalmente concebidos en las relaciones íntimas". Sin embargo, aunque se podría considerar el ajuste entre trabajador sexual y cliente una relación de negocio, similar a la que se produce entre consumidor y productor, comprador y vendedor (Tirado, p. 256), es imprescindible poner atención a su singularidad, ya que el mismo derecho a la libre disposición del cuerpo -puesto como justifi- cativa para la no criminalización del trabajador sexual-, puede ser invocado en cualquier momento, de manera unilateral, para retractarse sobre lo que va a pactar con el cliente.

Como representante del Ministerio Público en Brasil, tuvimos acceso hace unos años a un proceso en donde la víctima, una prostituta, después de ajustar la prestación del servicio, desistió luego de ver desnudo al cliente, alegando -según su testimonio en el proceso penal- haber encontrado marcas de lesiones en el miembro de su pareja. En aquel momento, la mujer fue forzada a realizar el acto sexual, lo que acabó por producirle lesiones de pequeña gravedad. Acusado de estupro, el "cliente" alegó el ejercicio de un derecho, ya que la relación había sido contratada regularmente, donde se entendía el rechazo como siendo parte de un "juego de seducción" utilizado por la mujer para excitarlo, de acuerdo con lo que ha declarado en juicio.

Los tribunales de Brasil entienden, en casos como el referido en el párrafo anterior, que la persona prostituida puede en cualquier momento retractarse sobre la relación "contratada", tal cual se ve en el juicio que se transcribe a continuación:

Estupro. Caracterização ainda que a vítima seja dada a vida licenciosa. Fato que não Ihe retira o direito de dispor do próprio corpo. Delito cujo bem jurídico tutelado é a liberdade sexual da mulher. Inteligência do art. 213 do CP. O bem jurídico que o 
art. 213 do CP protege é a liberdade sexual da mulher, é o direito de dispor do corpo, a tutela do direito de eleição sexual de que goza a sociedade. É direito seu que não desaparece mesmo quando se dá à vida licenciosa, pois, nesse caso, ainda que mercadejando com o corpo, ela conserva a faculdade de aceitar ou recusar o homem que a solicita (Mirabete, 2007, p. 1781).

\subsection{Prostitución y Derecho}

La posición del Derecho frente al trabajo sexual varía de un país a otro, como enseña el profesor Misael Tirado Acero (p. 258):

A nivel internacional, el Derecho mantiene diferentes posiciones frente al fenómeno, siendo posible distinguir cuatro modelos principales: el prohibicionista, el abolicionista, el reglamentario y el laboral, al ser común en estos modelos la persecución al delito de la prostitución forzada.

La prostitución está prohibida en muchos países, por lo que son descritos como prohibicionistas; es lo que sucede, por ejemplo, en gran parte del territorio de los Estados Unidos; otros, como Alemania, son clasificados como reglamentarios, adoptando una orientación opuesta y ofreciendo carácter oficial a la actividad de los profesionales del sexo, con la evidente finalidad de poder controlarla. Suecia cambió su legislación en 1999 y pasó a criminalizar tan solo la conduc- ta del "consumidor"; trató así, en última instancia, de enfrentar el fenómeno como una mera violencia contra la persona prostituida. Los datos disponibles dan cuenta de que el modelo sueco ha reducido en dos tercios la prostitución en las calles de Estocolmo, así como prácticamente ha extinguido la trata de personas con fines de prostitución en aquel país (Santis, 2013).

En América Latina predomina el modelo abolicionista, que consiste en la autorización en cuanto actividad individual, prohibiéndose, sin embargo, el estímulo o la explotación de la misma actividad por parte de terceros, tal cual ocurre en líneas generales en Brasil, Colombia y Argentina. Se sabe que se puede regular administrativamente la prostitución en las ciudades, estableciendo zonas o distritos con ella "compatibles" o delimitando el horario de funcionamiento y las características de los establecimientos destinados a su práctica*, pero seguramente es el Derecho Penal, como se va a examinar a continuación, el principal instrumento de que se socorren los Estados para su regulación.

En el contexto del modelo laboral merece destacarse la Sentencia T-629 de 2010 proferida por la Corte Constitucional de Colombia,

\footnotetext{
Sirve como ejemplo el Decreto Distrital 188 de 2002 Bogotá, referido en la Sentencia T-629 de 2010 de la Corte Constitucional de Colombia, p. 19, que dispone "sobre localización y funcionamiento de establecimientos dedicados al trabajo sexual. Incluyó específicas condiciones relacionadas con la salubridad, saneamiento, bienestar social, de seguridad medioambientales, de reglamentación hotelera, arquitectónica y urbanística".
} 
al analizar el pedido de tutela* presentado por Lais, una trabajadora sexual de Bogotá, contra el Disco Bar "Pandemo", de propiedad del señor Zoto, donde desempeñaba su actividad laboral y del cual fue despedida injustamente (sin derechos) al quedar embarazada. La demanda fue juzgada improcedente en primer y segundo grado, pero la Corte Constitucional, en un importante precedente, ha reformado esas decisiones, para reconocer los derechos laborales de la actora.

Aun sobre el modelo laboral, es interesante añadir que está en curso en la Câmara dos Deputados, en Brasil, una comisión parlamentaria de investigación, cuyo objetivo es averiguar el tráfico y el comercio de personas (tema que será abordado en la Sección 3 de este estudio). Aunque el informe final fue previsto solamente para los últimos meses de 2013, esta Comisión viene promoviendo muchos debates y audiencias públicas para abordar el tema de la legalización del trabajo sexual en Brasil (http://www2.camara.leg. br).

\subsection{Prostitución y sociedad}

En la esfera social es innegable la discriminación a que están sometidos los profesionales del sexo. Paulo Roberto Ceccarelli (2008) argumenta que "com a reforma religiosa do século XVI, o puritanismo passou a con-

\footnotetext{
La acción del empleado contra el empleador postulando el pago de sus derechos laborales que le han sido negados es conocido en Brasil como "Reclamatória Trabalhista" [Tutela Laboral].
}

trolar os costumes e ditar a moral", y desde entonces la prostitución, considerada como atentatoria a los valores fundamentales de la familia, fue lanzada a la clandestinidad. Cabe destacar una vez más, el magisterio del profesor Tirado Acero, al referir que en la ciudad de Bogotá se ha buscado la reglamentación, "lo que no necesariamente ha dado lugar a procesos de normalización dentro de la sociedad, una vez que lleva consigo fenómenos de exclusión social y estigmatización en torno de esta actividad económica" (Tirado, p. 249).

De todos modos, debemos añadir que la discriminación social recae de forma más aguda sobre los profesionales del sexo que trabajan expuestos, lo que no parece suceder con la llamada prostitución "de lujo", que se mueve de forma velada en las altas esferas del poder político y económico. Acerca de la hipocresía social frente a la prostitución, cabe destacar la canción "Geni e o Zeppelin", compuesta por uno de los más prestigiosos autores brasileños, Francisco (Chico) Buarque de Hollan$\mathrm{da}^{* *}$. En este poema se relata que en una cierta ciudad vivía Geni, una prostituta, a quien la sociedad local despreciaba, hasta el punto de cantarle en coro: "Joga pedra na Geni! Joga pedra na Geni! Ela é feita pra apanhar! Ela é boa de cuspir! Ela dá pra qualquer um! Maldita Geni!". Sin embargo, un día llegó al pueblo un enorme zepelín, con el propósito de destruirlo todo, pero su comandante, al ver a Geni, se dispuso a salvar la ciudad

\footnotetext{
** Probablemente inspirado en Guy de Maupassant, en el cuento "Bola de Sebo".
} 
a cambio de una noche con ella. Mas Geni sintió repulsión por el extranjero y se negó a acostarse con él, al que la ciudad empezó a repetir: "Vai com ele, vai Geni! Vai com ele, vai Geni! Você pode nos salvar! Você vai nos redimir! Você dá pra qualquer um! Bendita Geni!". Así que, resignada, aunque le costara muchísimo hacerlo, Geni accede a los deseos del invasor. Pero tan pronto el día siguiente amaneció y el zepelín partió, la ciudad volvió a entonar el refrán anterior.

La verdad es que tampoco las profundas transformaciones - de contenido marcadamente liberal- por las cuales está pasando la sociedad de nuestro tiempo, incluso en lo que concierne a la sexualidad, han sido suficientes para superar la desaprobación al comercio del cuerpo. Ciertos códigos de conducta, atrapados a una moral universalista, mantienen una visión estigmatizante en relación con los que practican sexo a cambio de un pago, una vez que entienden que no se puede hacer por dinero lo que solamente tendría lugar por afecto, aunque esta afección sea cada vez más superficial. En este contexto, cabe poner de relieve la enseñanza del profesor Misael Tirado Acero:

Estos códigos unificadores ponen de manifiesto las disidencias del mundo moderno en donde, a pesar de una propagación de la sexualidad públicamente aceptada, existen códigos que liberan las vacilaciones de lo deseable y aceptable frente a la censura y estigma de otro tipo de conductas sexuales del mundo contemporáneo (2011, p. 132).
Cierto es que de la discriminación resulta una fuerza de coerción, que puede quedar solamente en el ámbito social o alcanzar una condición de ilegalidad, tal como se extrae de la lección de Misael Tirado Acero, Wilmar Collazos y Carlos Martín Carbonell Higuera, al decir que "Los métodos de coerción van desde hacer el ridículo y recibir desaprobación pública, hasta ir a la cárcel” (2013, p. 102). Por otra parte, al ser innegable que los trabajadores sexuales operan bajo el "auspicio" de un público consumidor, a punto de permitir que la relación entre ellos se examine desde el marco de la economía de mercado, la discriminación se convierte en algo poco comprensible, ya que los consumidores pertenecen al mismo cuerpo social. Es decir,

vivimos en una sociedad de consumidores $y$, una vez que el trabajo y el consumo son solamente dos etapas de un mismo proceso impuesto al hombre por la necesidad de sobrevivir, esto es sólo otra manera de decir que vivimos en una sociedad de trabajadores (Arendt, 2011, p. 156).

\section{Explotación del trabajo sexual}

En el contexto de un modelo abolicionista, en que tanto el trabajo sexual y la práctica de su consumo son "indiferentes" al Estado, al menos bajo el punto de vista penal, la actividad represiva converge por entero para la lucha contra los comportamientos que, de una forma u otra, implican en especies de explotación, que pueden gravitar desde la simple práctica proxeneta, hasta la formación de or- 
ganizaciones criminales de alta complejidad, a punto de tener -lo que no es raro actualmente- características de transnacionalidad. De todos modos, estudiar la explotación sexual es hoy una tarea imposible, si no se tiene en cuenta la inmensidad de ofertas disponibles en el mercado, tanto en el aspecto cuantitativo como cualitativo, ya que al clásico modelo de la prostitución callejera, se han añadido "innovaciones" traídas por nuevas tecnologías como por ejemplo Internet. Por otra parte, en una evidencia mucho más grave, la actividad exploratoria ha extendido sus tentáculos sobre la sexualidad de los niños y de los adolescentes, así como ha caminado para la trata de personas, lo que implica, en la mayoría de los casos, reducir seres humanos a condiciones de esclavitud en pleno siglo XXI.

\subsection{Tratados y convenciones}

Desde finales del siglo XIX, organizaciones internacionales relacionadas con los derechos humanos han estado más atentas a la práctica del comercio sexual, impulsadas por señales evidentes de recrudecimiento de la explotación de personas prostituidas, como enseña Pablo Ceccarelli (2008):

Os primeiros movimentos internacionais contra a exploração sexual de mulheres e adolescentes começaram no final do século XIX. Em 1921 a Liga das Nações designou um comitê para tratar o problema do tráfico de mulheres e crianças; em 1946 a ONU adotou uma convenção a fim de erradicar a prostituição.
Al examinar los textos de los tratados y convenciones, se observa que el Derecho Penal se eleva invariablemente a la condición de primer instrumento de control recomendado por los Estados miembros, a fin de poner freno a la explotación del trabajo sexual. Es lo que sucede, por ejemplo, en el texto del “Convenio para la Represión de la Trata de Personas y de la Explotación de la Prostitución Ajena", adoptado por la Asamblea General en su Resolución 317, del 2 de diciembre de 1949, entrada en vigor el 25 de julio de 1951. En los cuatro primeros artículos de este ajuste los países signatarios se comprometen a castigar a los que inducen a alguien a ejercer la prostitución o le corrompen con objetivo de prostituirle, o aun, a los que explotan la prostitución, aunque eso ocurra con el consentimiento de la persona prostituida. El artículo 4으, por su parte, dice textualmente que tales prácticas deben ser consideradas actos delictuosos en el ámbito del Derecho interno de los Estados miembros. En el mismo sentido, otros ajustes internacionales se han seguido desde entonces, tales como, por ejemplo, la Convención sobre la Eliminación de todas las Formas de Discriminación contra la Mujer (Resolución 34/180, del 18 de diciembre 1979), y el Protocolo de 2000, de la Asamblea General, con el fin de prevenir, reprimir y sancionar la trata de personas, especialmente de mujeres y de niños.

\subsection{Explotación sexual en el Derecho Penal brasileño}

Desde hace mucho tiempo el Derecho Penal 
brasileño trata con mucho rigor las conductas de violación a la libertad sexual, especialmente el estupro*, que desde 1990 se ha considerado un crimen hediondo (Ley no $8.072 / 1990)$, y en esta condición pasó a ser sometido a mayor severidad en lo que respecta al cumplimiento de la pena. En agosto de 2009 , con la entrada en vigor de la Ley $\mathrm{n}$ $12.015 / 2009$, la legislación brasileña se ha vuelto aun más exigente, creando un capítulo especial sobre los "crímenes sexuales contra los vulnerables".

Concretamente, en lo que dice respeto a la explotación sexual, objeto del presente estudio, en la legislación brasileña están previstas penas (entre 2 y 5 años de prisión) para quien induzca, atraiga o facilite la prostitución o la explotación sexual de alguien, o para quien impida o dificulte la salida de alguien (Art. 228). Y la legislación de Brasil va más allá, estableciendo sanciones idénticas (entre 2 y 5 años de prisión) para los que mantuvieren un lugar destinado a la explotación sexual. El dispositivo cuenta con la siguiente redacción:

Art. 229. Manter, por conta própria ou de terceiro, estabelecimento em que ocorra exploração sexual, haja, ou não, intuito de lucro ou mediação direta do proprietário ou gerente.

* Acceder carnalmente a una persona, mediante constreñimiento alcanzado por el uso de la fuerza o de intimidación. Actualmente la ley brasileña denomina estupro (Art. 213) no solo la práctica forzada del acto sexual propiamente dicho, sino toda y cualquier práctica libidinosa que a ella se asemeje.
La norma en vigor, a pesar de haber reemplazado la expresión anterior (casa de prostitución) por otra similar (establecimiento en el que ocurra la explotación sexual), parece no haber modificado en nada la prohibición. El legislador brasileño, aunque sin criminalizar el meretricio, impone a sus practicantes el desabrigo de las calles, y por ello sufre una severa crítica de distinguidos jurisconsultos:

A exploração da prostituição, repetindo, é um dos comportamentos mais degradantes e moralmente censuráveis que a civilização, ao longo de toda a sua história, não conseguiu eliminar, a despeito de falsos moralismos de nossos legisladores, na medida em que a prostituição, em si, não constitui crime. Com a criminalização da manutenção de casa de prostituição (agora estabelecimento em que ocorra exploração sexual), paradoxalmente, o legislador penal proíbe a exploração de uma atividade que é permitida, e, confundindo moral com direito, "condena" a prostituição a realizar-se nas ruas, nos guetos, clandestinamente (Bittencourt, 2013, pp. 159-160).

La ley brasileña también contempla penas entre 1 y 4 años de prisión para quien practique el rufianismo, así considerado el "Tirar proveito da prostituição alheia, participando diretamente de seus lucros ou fazendo-se sustentar, no todo ou em parte, por quem a exerça" (Art. 230). Es fácil entender, que para 
que se dé el tipo penal, no es necesario que el agente influya en el libre albedrío, incentivando o restringiendo la víctima; basta, para la configuración del delito, tan solo con que el agente participe en los beneficios o que sobreviva a través de ellos. También en este punto la crítica doctrinal:

Na realidade, não deixa de ser também figura ultrapassada, pois o mundo moderno, inclusive em outros países, tem buscado a legalização da prostituição e, consequentemente, do empresário do setor. 0 rufianismo pode ser uma forma de proteção à pessoa que pretenda se prostituir (conduta não criminosa). Logo, ingressa nesse contexto o moralismo, por vezes exagerado, de proibir qualquer forma de agenciamento ou condução empresarial da atividade. A sociedade olvida o desatino de manter a prostituta nas ruas, sem proteção e vítima de violência, disseminando doenças, dentre outros problemas, em lugar de lhe permitir o abrigo em estabelecimentos próprios, fiscalizados pelo Estado, agenciados por empresários, com garantia tanto ao profissional do sexo quanto à clientela (Nucci, 2009, p. 85).

Parece no haber duda de que la ley penal brasileña va mucho más allá de otras legislaciones de América Latina. Así, por ejemplo, "mantener establecimiento donde ocurra la explotación sexual", o mera "participación en los lucros de la prostitución", son figuras que no encuentran correspondencia en Colombia o Argentina*. Creemos que la ley brasileña incurre en evidente exceso, al considerar delito (con pena entre 2 y 5 años de reclusión) el solo hecho de que alguien "mantenga establecimiento donde ocurra la explotación sexual", cuidando aun de añadir que la conducta será típica, independientemente de la intención de lucro o de mediación. Igualmente hay innegable exceso en la incriminación, a título de rufianismo, por el solo hecho de que alguien participe en los beneficios obtenidos por el trabajador sexual, considerando irrelevante el consentimiento de este y la existencia de un posible ajuste entre las partes.

La penalización de comportamientos, sin embargo, no puede considerarse una solución a todos los problemas. En este sentido, vale la pena recordar la sabia lección de David de Paiva Costa Tangerino, al afirmar que "o pensamento punitivo é um verdadeiro buraco negro que, em razão de sua gravidade extraordinária, atrai para o seu centro e ali desintegra qualquer luz que se pretenda lançar sobre o fenômeno criminal" (2011, p. 231). El Código Penal de Brasil, teniendo en cuenta el carácter prohibicionista de los dos dispositivos en cuestión, se opone a la razón y al libre albedrío, ofendiendo, en nuestra opinión, el principio de intervención mínima.

* El Código Penal de Colombia prevé, en sus artículos 213 y 214, pena para quien induzca o constriña a alguien a prostituirse, en cuanto la ley argentina, por su parte, en sus artículos 126 y 127, considera crimen tan solo si hubiere vicio del consentimiento, violencia, abuso, amenaza o cualquier otra forma de intimidación o coerción. 
2.3. Sentencia T-629 de 2010 (Colombia) y Derecho Penal

La decisión de la Corte Constitucional de Colombia, anteriormente mencionada en este trabajo, representa un marco importante en la preservación de los derechos fundamentales, en especial porque examina la dignidad de la persona humana sin la sombra de los prejuicios y de la hipocresía. Así, aunque admita que la prostitución constituye una llaga social, no niega su existencia milenaria, y menos aún muestra indiferencia a las condiciones socioeconómicas que normalmente le sirven de inspiración. Pero la pregunta que se hace es si, frente al Derecho Penal vigente, sería posible una decisión similar en Brasil.

Consta expresamente del precedente colombiano, que el señor Zoto admitió en su respuesta, ser de su propiedad la Discoteca "Pandemo", así como tratarse de un lugar destinado a la práctica de la prostitución; argumentó solamente, que la señora Lais frecuentaba el establecimiento en la condición de trabajadora sexual autónoma, sin horario establecido o vínculo de subordinación. Sin embargo, frente al Código Penal brasileño, el comportamiento confesado por el señor Zoto configuraría delito, castigado con prisión de 2 a 5 años, lo que creemos que implicaría inexorablemente un cambio radical en el curso de la discusión, transfigurándola de su enfoque original (Derecho Laboral) y sirviendo como obstáculo a la protección de los derechos fundamentales, tal como ocurrió en el juicio.
Nos parece que, infelizmente, la Sentencia $629 / 10$ no encontrará correspondiente similar en Brasil, al menos en cuanto estén en vigor los anticuados dispositivos penales (artículos 229 y 230). Hemos consignado, anteriormente (Sección 1), que la legalización del trabajo sexual está en discusión en la Câmara dos Deputados, de Brasil; sin embargo, tal debate pierde la razón, si no hubiere la regulación de la actividad de los intermediarios comerciantes, mantenedores de establecimientos destinados a la práctica de esta actividad. En este caso, los legisladores tendrán que revocar los dispositivos penales en cuestión, so pena de llegarse a una situación inusitada en que una actividad, aunque lícita, impondrá a sus trabajadores la limitación de solo poder practicarla de forma autónoma.

\subsection{Explotación sexual de niños y adoles- centes}

En lo que concierne a la explotación sexual, nada puede ser más grave -ni más repugnante- que el envolvimiento de niños $y$ adolescentes; sin embargo, ello es noticia frecuente. Se sabe que hay un universo de "consumidores", procedentes sobre todo de Europa, que desafortunadamente calientan el mercado y contribuyen para que se recluten cada vez más y más niños para vender sus cuerpos. Esto ocurre especialmente en países y/o regiones donde hay una acentuada desigualdad social, siendo frecuente en las calles y plazas de las grandes y medianas ciudades brasileñas, e incluso en establecimientos comerciales, a pesar del rigor de la 
ley penal, como veremos. En 2006, la Polícia Rodoviária Federal, en reportaje ampliamente difundido por los medios de comunicación, estimó en 1.200 los lugares de prostitución infantil en las carreteras de Brasil, destacando el papel de los intermediarios, a menudo personas de la propia familia de los niños, incluso algunos casos puntuales intermediados por la propia madre. Merece la pena poner atención a lo que dice Paulo Ceccarelli (2008):

Realidade ainda mais triste é a prostituição infantil que assola a sociedade brasileira. Presente nas camadas mais pobres dos grandes centros urbanos, sobretudo nas capitais do norte e nordeste do Brasil, assim como em regiões isoladas do país marcadas por atividades extrativas, supõe-se que o número de meninas envolvidas nessa atividade chegue aos 500 mil.

No es reciente la preocupación de los organismos internacionales con la explotación sexual de los jóvenes, alcanzados por el comercio del cuerpo aún en la minoridad. Prueba de ello es el Congreso Mundial sobre la Explotación Sexual de Niños y Adolescentes, realizado en Estocolmo, en 1998, cuya finalidad ha sido, entre otras, incumbir los Estados miembros de "Divulgar, como materias delictivas, criminales, la explotación sexual y comercial de los niños, así como otras formas de explotación sexual, condenando y castigando todos los delincuentes involucrados". Debido a la gravedad del problema y frente a la presión internacional para la rea- lización de tratados en donde el país figura como signatario, la ley penal brasileña ha recrudecido el combate a la explotación sexual de niños y adolescentes, culminando con la reforma de 2009, cuando entró en vigor el actual Art. 218-B, que recomienda pena entre 4 y 10 años de prisión, tanto para quien induzca o atraiga a la prostitución a persona menor de dieciocho años, así como para la que mantuviere relaciones sexuales (consumidor) en esta circunstancia. De nuevo, a modo de comparación, cabe señalar que la legislación brasileña es, en este punto, mucho más suave que la colombiana, en donde las penas varían entre diez y veinticinco años de prisión en estos casos*.

\section{Trata de personas}

El primer instrumento internacional (global) sobre la trata de personas es originario de la Convención de las Naciones Unidas contra la Delincuencia Organizada Transnacional, conocida como la Convención de Palermo, posteriormente complementada por el Protocolo específico. En este documento los Estados miembros se comprometieron a definir los delitos y a cooperar entre sí en la investigación y en los procesos relativos al tráfico, prestando asistencia a las víctimas. Sin embargo, desde su entrada en vigor, el comer-

* El Código Penal colombiano, en los artículos 217 a 219-B, prevé penas rigurosas en relación a conductas ligadas a explotación sexual de persona menor de dieciocho años, tipificando desde el estímulo a la prostitución propiamente dicho hasta la práctica de lo que denomina "turismo sexual envolviendo menores", cosa cada vez más frecuente en países de América Latina. 
cio de personas aumentó cualitativamente y cuantitativamente, lo que no sorprende, teniendo en cuenta las cifras publicadas por las Naciones Unidas, diciendo que circulan "por lo menos 32 mil millones de dólares al año". No siendo eso suficiente, el informe publicado por UNODC (United Nations Office on Drugs and Crime) en diciembre de 2012, nombrando a 132 países, estima que un tercio de las víctimas de la trata de personas detectada oficialmente en el mundo entre 2007 y 2010 son niños (http://www.onu. org.br). Esta realidad dramática fue traída a la discusión en la Asamblea General de la ONU, el 17 de mayo de 2013, en Nueva York, oportunidad en donde las 85 naciones presentes, convergieron con el fin de concentrar esfuerzos para una acción coordinada contra lo que llamaron "la esclavitud moderna". En esa ocasión, el director ejecutivo de UNODC, Yury Fedotov, dijo en su discurso: "Estamos frente a una delincuencia del siglo XXI: adaptable, cínica, sofisticada, que existe en países desarrollados y en desarrollo" (Fedotov, 2013). Verdad es que la trata de personas ha alcanzado proporciones alarmantes y desafía las autoridades: en 2005, un Informe de la Organización Internacional del Trabajo ha estimado en 2,5 millones el número de personas víctimas de la trata en todo el mundo, de las cuales el $43 \%$ corresponde a la explotación sexual y un 25 \% para la exploración sexual y económica (Sakamoto, 2013).

De acuerdo con la definición de las Naciones Unidas, la trata de personas puede ser entendida como el proceso mediante el cual estas son "reclutadas" en su comunidad y explotadas por los traficantes que las engañan y/o usan alguna forma de coerción para atraerlas y controlarlas. El Protocolo para Prevenir, Suprimir y Punir el Tráfico de Personas, en Especial Mujeres y Niños, complementado por la Convención de Palermo, define la trata de personas en los siguientes términos:

La captación, el transporte, el traslado, la acogida o la recepción de personas, recurriendo a la amenaza o al uso de la fuerza u otras formas de coacción, al rapto, al fraude, al engaño, al abuso de poder o de una situación de vulnerabilidad o a la concesión o recepción de pagos o beneficios para obtener el consentimiento de una persona que tenga autoridad sobre otra, con fines de explotación de la prostitución ajena u otras formas de explotación sexual, los trabajos o servicios forzados, la esclavitud o las prácticas análogas a la esclavitud, la servidumbre o la extracción de órganos*.

La regla es que el tráfico humano, especialmente aquel cuyo propósito sea la explotación sexual, reclute sus víctimas, en su mayoría mujeres, entre la población joven (15-21 años) de las comunidades pobres, en donde el sueño de emigrar en busca de mejores condiciones de vida y trabajo es frecuente. Engañadas por falsas promesas, atraídas por la expectativa de trabajos bien pagados y, otras veces, el aprendizaje de len-

Artículo 3. Definiciones, numeral "a". 
guas extranjeras, hace que las presas solo se den cuenta de la acción de los criminales, cuando ya están sometidas a un régimen de verdadera esclavitud, lejos de sus familias $y$, a menudo, lejos de sus países de origen. De acuerdo con el informe de UNODC, como se mencionó anteriormente, existen importantes variaciones regionales, que deben ser consideradas para el estudio adecuado de la trata de personas: así, por ejemplo, mientras en África y Asia predominan los casos de explotación del trabajo forzado, en las Américas la explotación sexual se destaca entre los propósitos más frecuentes y, también, como ya hemos referido, alcanzando un gran número de niños.

\subsection{Trata de personas y represión penal}

Aun teniendo en cuenta el informe de UNODC, en este documento se reconoce que hay muchas lagunas sobre la verdadera magnitud de la trata de personas, ya sea en cuanto al conocimiento de las técnicas adoptadas por las organizaciones que se dedican a esta práctica criminal, sea por las dificultades para obtener datos más amplios sobre los infractores, las víctimas y los flujos migratorios. Aun así, los números conocidos son alarmantes y la Agencia estima que existen millones de víctimas. Por otro lado, el informe también advierte sobre los bajos índices de condenación de los responsables, ya que el $16 \%$ de los países estudiados no registraron ni una sola condena entre 2007 y 2010, mientras que en América del Sur este porcentaje (de países que no han registrado condenas) excede el $20 \%$. Por otra parte, incluso entre los países que han sido considerados más exitosos, el número de condenas no ha superado cincuenta casos por año, demostrando que la represión penal encuentra obstáculo tanto en la oscuridad que envuelve el delito, cuanto en la complejidad y en la lentitud del proceso.

Un estudio realizado en Perú, sobre procesos criminales por la trata de personas, ha concluido, de forma no alentadora (Cavassa, 2011), que en los casos investigados la identidad de las víctimas no ha sido debidamente preservada; además, en ninguno de los casos, las víctimas han tenido acceso a servicios de protección. La no preservación de las víctimas aumenta el daño y multiplica el riesgo de represalias; y la no protección, a su vez, trae serias y graves implicaciones con respecto a la realización de las pruebas en casos futuros, visto que el estado de vulnerabilidad se difunde entre las personas involucradas. En los comentarios finales de este trabajo, sus autores adjetivarán el tráfico de personas como siendo un delito "subterráneo", teniendo en cuenta su escasa evidencia y la dificultad de colectar pruebas en el proceso penal:

Decimos que es subterráneo porque independientemente de que los espacios de transacción (que permiten la comercialización de la víctima) sean informales y, por lo tanto, medianamente aceptados en una población poco formal como la latinoamericana. Hay adicionalmente una pesada 
carga cultural de relativa aceptación con

respecto a las situaciones de dominación

de unos seres humanos por otros.

Otro importante estudio ha investigado un significativo número de mujeres dominicanas que se prostituían en Argentina (Organización Internacional para las Migraciones, 2003). Se sospechaba que estas mujeres podrían ser víctimas de la trata de personas, pero el resultado final fue que habían ingresado al país en la condición de turistas, con documentación legal y debidamente presentada a las autoridades de inmigración. Se ha concluido, entonces, que en tales circunstancias no habría tráfico, a pesar de que la permanencia de estas extranjeras podría tornarse ilegal en poco tiempo dada la naturaleza de la visa (turismo), pero eso por sí solo no sería suficiente para caracterizar frente al concepto de los tratados y convenciones, la condición de víctima de tráfico.

Del precedente argentino se extrae que emigrar voluntariamente, aunque con intención de burlar el visado permanente en un determinado país y no obstante con el único propósito de practicar la prostitución, no configura por sí mismo la trata de personas, conducta que requiere la participación de múltiples actores y en que, de una u otra manera, la víctima deberá estar sometida a vicio del consentimiento. Es de destacar, sin embargo, que este mismo estudio ha reconocido, en el informe final (p. 82), la comprobada acción de "coyotes" con quienes las inmigrantes habían contraído grandes deudas, así como de otros agentes de coacción interrelacionados, tales como "el reclutador, sus emisarios, sus compañeras de pensión, el dueño de la pensión, los dueños/administradores de los bordelés y los casos en que las mujeres fueron encerradas", pero que, aun así, no se habría caracterizado la trata de personas, porque las extranjeras se prostituyen del mismo modo como lo hacen las argentinas, de manera que la lógica del negocio prevalece sobre la lógica de la nacionalidad.

Es importante tener en cuenta, que la trata de personas se efectúa, invariablemente, con la reducción de la víctima a una condición análoga a la esclavitud, pues de una forma u otra es llevada a hacer lo que no quiere, o es impedida de abandonar esa actividad, a la cual es sometida por las circunstancias que sirven a la finalidad económica que mueve la acción de los criminales.

Desconocemos la legislación penal de cualquier país democrático que no considere delito la reducción de alguien a la condición de esclavo, aunque la forma de definición del tipo penal pueda dar lugar a diferentes interpretaciones en cuanto a comportamientos específicos ${ }^{*}$. Así que, sin pretender cuestionar la incidencia del Art. 140 de la ley pe-

\footnotetext{
En Brasil, el Art. 149 del Código Penal (pena de 2 a 8 años de prisión) especifica lo que se considera reducción a la condición de esclavo: someter a trabajos forzados o a jornada exhaustiva, o a la condición degradante de trabajo; o restringir de cualquier modo la locomoción en razón de deuda contraída con el jefe o su representante. En el derecho argentino, el Art. 140 del diploma, aunque previendo pena más severa (4 a 15 años), es genérico en lo que toca a constricción, utilizando tan solo la expresión bajo cualquier modalidad.
} 
nal argentina en el caso concreto, frente al código brasileño, el caso de las mujeres dominicanas configuraría, al menos en teoría, una reducción a la condición de esclavitud, teniendo en cuenta que la deuda contraída con los "coyotes" fue el factor determinante de su prostitución.

De este modo, tal como ocurre con respecto a la explotación sexual (Sección 2 de este trabajo), es evidente el endurecimiento de la legislación penal en los países de América Latina también con relación a la trata de personas, y la pena impuesta es invariablemente grave. Esto se debe al hecho de que, como hemos visto antes, los tratados y convenciones obligan a los Estados miembros a adoptar políticas para frenar la trata de personas y la explotación sexual, y la criminalización de conductas o la elevación de las penas, aparece como la primera alternativa en este sentido.

En Brasil, tanto el tráfico interno y el internacional (con el propósito específico de prostitución) están tipificados en el Código Penal desde 2005, que ha sido modificado por la legislación en 2009 (Ley no 12.015). Vale destacar, sin embargo, que el bien jurídico protegido por la criminalización de la conducta de tráfico de seres humanos, es la libertad en sus más diversas formas ("la libertad sexual, la libertad de ir y venir, la libertad laboral") (Salgado, 2007, pp. 3/5), no pudiendo la ley penal quedar restringida a reprimir tan solo uno de ellos.

\section{CONSIDERACIONES FINALES}

De todo lo que hemos visto en este breve estudio, algunas conclusiones parecen inevitables en lo que concierne al ejercicio de la prostitución y la explotación sexual que de ella puede advenir, empezando por la reflexión que se impone a partir de la Sentencia T-629 de 2010, de la Corte Constitucional de Colombia. Siendo el trabajo sexual una realidad, y ante un modelo abolicionista, en que esta práctica no constituye ningún acto ilegal, el reconocimiento de derechos a aquellos que se dedican a esta actividad, debe ser visto como un deber, con respecto sobre todo, a la propia dignidad de la persona humana. Por otra parte, la razonabilidad recomienda avanzar hacia la regulación por parte del gobierno, no solo por cuestiones tributarias o laborales, sino también porque la omisión estatal condena a la clandestinidad una legión de personas, exponiéndolas, ahí sí, a la explotación practicada por "empresarios" sin escrúpulos.

Por otra parte, la explotación sexual es una actividad que mueve millones de dólares cada año en el mundo, extendiendo sus tentáculos sobre todo en países de América Latina, donde niñas -cada vez más jóvenes- son capturadas y "consumidas" por un mercado cada vez más generalizado. El principal problema está en el hecho de que los "turistas sexuales" extranjeros, provenientes principalmente de Europa y Norteamérica, encontrados hoy por hoy a "simple vista" en muchas playas del nordeste brasileño, a me- 
nudo están mediados por redes que vician el consentimiento de las personas a ellas sometidas, que en gran parte son menores de edad e incluso niños.

Igualmente grave es la trata de personas con fines de explotación sexual, sea en el ámbito interno de los países, sea en el plano internacional. Criminales, cada vez más estructurados y organizados, suelen atraer las víctimas con falsas promesas de una vida mejor en otro país o región, de matrimonios "convenientes", fama o viajes; y cuando esas víctimas se dan cuenta del engaño ya son vulnerables y sometidas a explotación, también bajo múltiples formas de constricción, desde el cautiverio convencional, hasta el uso de familiares -a menudo los hijos-como rehenes.

Se sabe que en tales casos la vulnerabilidad de las víctimas termina obstaculizando el desempeño del Estado (tanto en la represión, cuanto en la protección), especialmente en el contexto internacional, en el que la víctima se encuentra, en gran parte de los casos, en situación de ilegalidad frente a las leyes de inmigración. Por lo tanto, el debilitamiento de las víctimas termina sirviendo como una herramienta para que los delincuentes las sometan a situaciones extremas. En el momento en que se llevó a cabo este estudio, la prensa brasileña informó la detención, en el interior de Rio Grande do Sul, de una mujer que seducía adolescentes bajo la promesa de altos salarios para trabajar en la construcción de la central hidroeléctrica de Belo Monte; llegando al interior del estado de Pará, sin embargo, lugar difícil de acceder, las víctimas eran obligadas, por otros miembros de la organización criminal, a prostituirse con los trabajadores de la usina, permaneciendo encerradas por la noche, incluso sin acceso a la electricidad (Jornal Zero Hora, 2013, p. 34).

En varios puntos de este estudio hemos destacado que los tratados y convenciones suelen hacer referencia explícita a la ley penal, imponiendo a los Estados miembros el compromiso de tipificar conductas, con el fin de enfrentar la explotación sexual y la trata de personas. Pero hay que poner atención en el hecho de que la actividad de la ley penal es esencialmente represiva, y por más que se reconozca el carácter pedagógico de las penas en esta área, su eficacia en cuanto instrumento modificador de la conducta es bastante limitada. Los problemas encontrados al analizar los casos ocurridos en Perú, mencionados en el presente trabajo, no desentonan, seguramente, de lo que se podrá verificar en otros países de Latinoamérica: procesos prolongados, extrema dificultad en la producción de pruebas, víctimas no preservadas, etc. Hay que tener en cuenta que el Derecho Penal debe ser adoptado como la ultima ratio, lo que obliga a buscar socorro en otras políticas, especialmente en lo que respecta a la educación y la lucha contra la pobreza, evitando la expansión indiscriminada de tipos penales, en una práctica que 
podría llamarse de "criminalización de la política social”*.

No obstante, al menos en Brasil hay una importante tendencia legislativa hacia la ampliación del ámbito penal, tal vez porque el Estado descuide de las políticas de prevención. La trata de personas, por ejemplo, tiene su práctica facilitada por la exclusión social, pero también por ignorancia y por falta de una política de Estado, cuyo propósito sea prevenir el público vulnerable sobre las actividades de los delincuentes.

Pero para demostrar lo común que es entre nosotros recurrir al Derecho Penal como una solución para todos los males, vale la pena recordar que la Comisión Parlamentaria de Investigación -(CPI) de la Trata de Personas en Brasil-corriendo en la Câmara dos Deputados, ya mencionada en este estudio (Secciones 1.1 y 2.3), aunque con un informe, ya da señales de que irá a sugerir la tipificación de nuevas conductas y el agravamiento de las penas.

\section{REFERENCIAS}

Arendt, H. (2010). A Condição Humana, 11a edição. Rio de Janeiro: Forense Universitária.

Bittencourt, C. R. (2013). Tratado de direito Penal. Parte Especial 4, 5a edição. São Paulo: Saraiva.

Alejandro Aponte. Coordinador Nacional del Proyecto "Lucha contra la trata de Personas en Colombia". Oficina de las Naciones Unidas contra las Drogas y el Delito, Bogotá, Colombia.
Cavassa, R. (2011). El proceso penal peruano en el delito de trata de personas - 14 casos en Lima y Loreto. ONG Capital Humano y Social Alternativo (CHS Alternativo). ISBN 978612-45580-6-1, Lima.

Ceccarelli, P. R. (dez 2008). Prostituição - Corpo como Mercadoria, Revista Mente e Cérebro-Sexo, 4 (edição especial), Ed. Duetto.

Fedotov, Y. Boletim UNODC. Disponible en http://www.unodc.org/lpo-brazil/pt/ frontpage/2013/05/17-general-assembly-reviews-efforts-to-combat-human-trafficking. html, accedido el 20/8/2013, 19 horas.

Mirabete, J. F. (2007). Código Penal Interpretado, 6a Ed. São Paulo: Atlas.

Nucci, G. de S. (2009). Crimes Contra a Dignidade Sexual. Comentários à Lei 12.015, São Paulo, Revista dos Tribunais.

Sakamoto, L. O tráfico de seres humanos hoje. Disponible en http://www2.uol.com. br/historiaviva/artigos/o_trafico_de_seres_ humanos_hoje.htm, accedido en 21/8/2013, 12 horas.

Salgado, D. de R. (Jan 2007). O Bem Jurídico Tutelado pela Criminalização do Tráfico Internacional de Seres Humanos. Brasília. Boletim dos Procuradores da República (72), 3/5.

Santis, M. Woman's Justice Center - La solución de Suecia para la prostitución: ¿por qué nadie intentó esto antes? Disponible en 
http://pt.scribd.com/doc/87822699/A-Solu- econômicas. Revista Prolegômenos, XIV(27), cao-Da-Suecia-Para-a-Prostituicao-e-Sexo-e 247/263. Bogotá, D.C. Colômbia. ISSN: 0121Mercado, accedido en 13/08/2013, 22 horas. 182X.

Tangerino, D. de P. C. (2011). Culpabilidade. Tirado Acero, M. (2011). El debate entre Rio de Janeiro: Elsevier Editores. prostitución y trabajo sexual. Una mirada desde lo socio-jurídico y la política pública, Tirado Acero, M. (2010). Comercio sexual. Revista de Relaciones Internacionales, EstraUna mirada desde la sociología jurídica. tegia y Seguridad, 6(1), 127/148. Bogotá, CoLima, Bogotá: Instituto Internacional de De- Iombia.

recho y Sociedad, IIDS. Fundación FEFSA.

Tirado Acero, M., Collazos, W. P., Carbonell Tirado Acero, M. (2011). Implicações do TraHiguera, C. M. (2013). La investigación jurídibalho Sexual como Atividade Legalmente ca y sociojurídica. Precisiones y claves. UniReconhecida. Um acercamento ao trabalho versidad Militar Nueva Granada.

sexual desde suas dimensões sociológicas e 